\title{
'It's Easier Said Than Done': Perspectives on Mammography From Women With Intellectual Disabilities
}

\author{
Joanne E. Wilkinson, MD, MSc $\mathrm{c}^{1,2}$ \\ Cristina E. Deis, BS $S^{1,2}$ \\ Deborab J. Bowen, PhD ${ }^{2}$ \\ Barbara G. Bokbour, PhD ${ }^{3,4}$
}

'Department of Family Medicine, Boston University School of Medicine, Boston, Massachusetts

${ }^{2}$ Department of Community Health Sciences, Boston University School of Public Health, Boston, Massachusetts

${ }^{3}$ Department of Health Policy and Management, Boston University School of Public Health, Boston, Massachusetts

${ }^{4}$ Center for Health Quality, Outcomes and Economic Research, ENRM Veterans Affairs Medical Center, Boston, Massachusetts

Conflicts of interest: authors report none.

\section{CORRESPONDING AUTHOR}

Joanne E. Wilkinson, MD, MSc

Department of Family Medicine, Dowling 5

Boston University School of Medicine

840 Harrison Ave

Boston, MA 02118

Joanne.Wilkinson@bmc.org

\begin{abstract}
PURPOSE Women with intellectual disabilities (or mental retardation) are living longer, receiving primary care in the community, and have equal rates of breast cancer compared with women in the general population, but they have lower rates of mammography. Although several public campaigns have successfully raised the mammography rate for racial and ethnic minority women, they have not penetrated the community of women with intellectual disabilities. No research to date has explored potential barriers to mammography for these women by involving the women themselves as participants.
\end{abstract}

METHODS We undertook a qualitative study to explore the perceptions and understanding of mammography for women with intellectual disabilities and some of the potential reasons they would or would not have the test. Twentyseven intellectually disabled women were recruited through a variety of community groups and interviewed using a semistructured interview guide. Data were analyzed using qualitative techniques from grounded theory.

RESULTS Participants in this study described being poorly prepared for mammography: they did not understand its purpose and were not prepared for the logistics of the experience. The latter was more upsetting to participants and contributed to their negative perceptions of mammography. Participants reported feeling unprepared and singled out for being unprepared, despite their desire to have at least 1 mammogram, as do other women their age.

CONCLUSIONS Women with intellectual disabilities perceive mammography differently than do women who do not have intellectual disabilities, and their perception is informed by inadequate knowledge, anxiety, and inadequate preparation. These themes should be considered when planning cancer prevention interventions with this population and when counseling individual women in the clinical setting.

Ann Fam Med 2011;9:142-147. doi:10.1370/afm.1231.

\section{INTRODUCTION}

dults with intellectual disabilities (formerly mental retardation) are
a medically underserved population who experience disparities in
screening and preventive care. ${ }^{1,2}$ Intellectual disabilities are defined as having an intelligence quotient of 2 or more standard deviations below the mean and demonstrated difficulties in 2 or more adaptive areas of daily living. ${ }^{3}$ There are approximately 8 million persons with intellectual disabilities in the United States. ${ }^{4}$ Fifty percent are women, and many adults, now deinstitutionalized, ${ }^{5}$ receive primary care in community practices.

Women with intellectual disabilities are now living longer, to a mean age of 66 years. ${ }^{6}$ Researchers have noted health disparities for these women, ${ }^{7}$ especially in prevention and screening. ${ }^{8,9}$ Although women with intellectual disabilities get breast cancer at the same rate as the general 
population, ${ }^{10,11}$ their rates of timely mammography (within the past 2 years) have been as low as $12 \%$ in recent studies. ${ }^{12,13}$ Little is known, however, about the reasons for these low rates.

In a recent study from Australia, ${ }^{13}$ geographic area (rural), marital status (unmarried), and severity of the intellectual disability were all associated with lack of timely mammography. One study using focus groups to explore the health of intellectually disabled women ${ }^{14}$ reported that many women had stopped going for mammograms because their experiences were upsetting. For women of normal intelligence from ethnic minority groups, fear of the results, lack of insurance, trust in their physician, a sense of fatalism, and embarrassment about undergoing the test affected their likelihood of obtaining a mammogram. ${ }^{15-17}$ Other studies focusing on intellectual disabilities found, after interviewing caregivers ${ }_{1}^{18,19}$ that lack of staff knowledge and lack of physician recommendation were barriers to mammography. No research to date, however, has examined obtaining mammograms from the perspective of intellectually disabled women. Our project aimed to understand decisions about mammography from the perspective of women with intellectual disabilities and to explore aspects of their knowledge, experiences, and expectations leading to a decision to have or not have a mammogram.

\section{METHODS}

\section{Participants}

We recruited a purposive sample of women with intellectual disabilities who were eligible for mammography in 2007 and 2008 (who were older than 40 years, or younger than 40 years with a family history of breast cancer) and had sufficient verbal skills to participate in a qualitative interview. Women were recruited from a state self-advocacy program, 2 large providers of residential and day services, and the Arc of Massachusetts. Because women with intellectual disabilities are rarely included in research studies, we were concerned that in contacting them we could create a therapeutic misconception that we were providing health care. We sent an e-mail to the community organization explaining the study in general terms and asking whether any of their female clients aged 40 years or older would be candidates for participation. If there were candidates, a member of the organization approached the women to ask whether they could be contacted by the study staff. Once the organization had relayed the permission, the study staff called and arranged to meet the potential participant.

The consent process was conducted in person because it was possible that not all potential participants would be able to give consent for themselves.
Some participants (7 of 27) had a guardian or legally authorized representative. For those women, we obtained their assent (to make sure they were interested in participating) and formal consent from their guardian or representative. For the remaining women, consent was obtained as follows. The researcher introduced the idea of the study and what would be expected, emphasizing that participation was voluntary and that the participants did not have to answer any questions they did not want to. The participants were then asked to describe the study and their role to the researcher in order to demonstrate a good understanding of their role before their consent was obtained. The recruitment and consent process was approved by the Boston University Medical Campus Institutional Review Board and monitored by a Data Safety Monitoring Board.

\section{Data Collection}

We used a semistructured interview guide that addressed the following general topics: (1) the participant's life and general level of independence, $(2)$ the participant's relationship with her physicians and the communication with her physicians; (3) the participant's experience getting tests done that were ordered by her doctor, and (4) the participant's specific experience with the mammogram, and why she did or did not complete mammography screening (Supplemental Appendix 1, available online at http:/www.annfammed.org/ cgi/content/full/9/2/142/DC1). Participants were asked open-ended questions about each area, followed by more detailed prompts. The interview was also flexible enough to follow up on topics introduced by participants in response to the open-ended questions. The capacity to be interviewed and the responses of the women who had and did not have legally authorized representatives were comparable throughout the study.

\section{Analysis}

We conducted analyses using techniques informed by grounded theory methods. ${ }^{20}$ The interviews were transcribed verbatim and initially coded by 2 members of the research team (J.E.W., C.E.D.) line by line with 1- or 2-word summaries of the content. Next, those codes were reviewed jointly by the 2 coders and grouped into second-level codes (categorizing or defining them more broadly). Third, the second-level codes were reviewed and grouped as themes were identified from the data. As we began to identify themes using an iterative process, we continued to return to the data to confirm their meaning. Each step in this process or level of coding was reviewed by at least 2 researchers.

Participant names were changed to pseudonyms for the purposes of this article and other presentations about this project. 


\section{RESULTS}

We interviewed 27 women, at which point we reached thematic saturation. Their ages ranged from 27 to 69 years ( 1 participant was younger than 40 years but had a family history of breast cancer). Other demographic characteristics are displayed in Table 1: $59 \%$ of women interviewed were aged between 51 and 60 years, 11\% were African-American, and the group was evenly split between women living independently (52\%) and living in group homes (48\%). Although the interview focused on mammography, we also asked women to describe a typical day in their lives and found that they spoke with confidence about their usual level of independence.

Meg (54 years): I am the secretary at ——_. I'm there for, around, 3 and a half hours, um, until around 2 o'clock in the afternoon... I wait for my fiancé to call me to see how his day went, um, and then the routine starts all over again.

Interviewer: Now does anyone help you with some of the daily day-to-day things?

Meg: Um, no, I live by myself. I do my laundry, I do my bills.

Interviewer: What kind of stuff do you normally do at work?

Lisa (47 years): Collating, mailing, putting stamps on the envelopes, trifold, put 'em in envelope, seal them.

Although the complexity of the day varied among participants, they described it with a sense of mastery and emphasized that they accomplished most tasks without help.

When discussing their experiences of mammography, however, the women expressed several concerns relating to feelings of incompetence, as well as a desire to fit in with other women. Several themes emerged:

(1) not understanding the purpose of mammography,

(2) feeling unprepared for mammography, (3) having

\begin{tabular}{|c|c|c|c|}
\hline Characteristic & $\begin{array}{l}\text { Group Home } \\
(n=13) \\
\text { No. }\end{array}$ & $\begin{array}{c}\text { Independent } \\
(n=14) \\
\text { No. }\end{array}$ & $\begin{array}{c}\text { Total } \\
\text { No. }\end{array}$ \\
\hline \multicolumn{4}{|l|}{ Age, y } \\
\hline$<40^{\mathrm{a}}$ & 0 & 1 & 1 \\
\hline $40-50$ & 2 & 3 & 5 \\
\hline $51-60$ & 11 & 5 & 16 \\
\hline $61-70$ & 0 & 5 & 5 \\
\hline \multicolumn{4}{|l|}{ Race } \\
\hline White & 11 & 13 & 24 \\
\hline Black & 2 & 1 & 3 \\
\hline \multicolumn{4}{|l|}{ Consent status } \\
\hline Independent & 6 & 14 & 20 \\
\hline With guardian & 7 & 0 & 7 \\
\hline
\end{tabular}

ane participant was younger than 40 years but had a family history of breast cancer. motivations for at least 1 mammogram, and (4) feeling singled out during the test.

\section{Lack of Understanding the Purpose of Mammography}

Several participants lacked accurate information about breast cancer or mammography. They reported being told by their physician that they were due for a mammogram but not what a mammogram was. One participant finally felt comfortable enough halfway through the interview to admit that she did not know what cancer actually was, despite agreeing to be interviewed about having mammograms.

Interviewer: Do you know what cancer is?

Gail (67 years): No.

Interviewer: Cancer is....

Gail: It's a sickness?

Interviewer: Yup, it's a sickness.

Gail: Is it something bad?

This participant had little understanding of the relationship between mammograms (which she recognized and had had) and cancer (a more abstract concept to her). The unmasking of participants' lack of knowledge tended to happen late in the interview, presumably after they had become comfortable with the interviewer. Some participants also discussed their frustration with their physicians, who did not seem to understand the depth of their knowledge deficit.

Meg: You see, like, there was some doctors say you got to do this and that to your breast, but I don't even know what they're talking about! .... If you had a mummy, maybe that would be a lot benifactual to me in showing me than saying you gotta do this and do that....

Meg's confusion about how to perform breast self-examination is evident. She could suggest how her physician could make the teaching easier (using a dummy to demonstrate), but she is clearly frustrated by the kinds of explanations she is getting. Other participants also voiced recommendations about how they might increase their understanding (Table 2).

\section{Feeling Unprepared for the Experience}

Many participants spoke of being uninformed not only about the purpose of the mammogram but also about what to expect during the test (what would happen, how long it would take, where it would be).

Interviewer: How did you know want it was going to be like? Polly (46 years): Because I know operation looks on hospital programs.

Interviewer: Was it what you expected? 
Polly: No! I though they were going to put something down there [referencing a gynecologic examination].

Interviewer: Do you remember a time when your doctor talked to you about it?

Daisy (54 years): Yeah.

Interviewer: Yeah. And what did your doctor say?

Daisy: She says to me, "Oh don't worry, it's not gonna hurt."

Interviewer: $\mathrm{Oh}$ your doctor said, "don't worry, it's not going to hurt?"

Daisy: It's easier said than done.

The participants had varying expectations of the proceduresome of which were inaccurate, like Polly's. When they discussed the gap between their expectations and the experience, many expressed frustration at their physician for not preparing them better.

Interviewer: Now, when you found out about this test, what did your doctor say?

Jen (57 years): He said just don't be afraid, just be brave.

Interviewer: Did he tell you what the test was going to be? Jen: No, ma'am

Alice (53 years): Many people with intellectual disabilities... don't really understand what a mammogram is about, and if it was explained to them and explained that it's gonna hurt but this is what it's for, um... maybe it wouldn't be so hard on them.

Gail: It's important that I know ahead of time instead of a week later, or not knowing at all!

Both the participants' frustration about not being prepared and distrust in the communication that resulted in their lack of preparation comes through in these statements. One participant, 51-year-old Dora, explained that she has had several mammograms and feels confident about it ("I know what it's like because I have them all the time" ${ }^{\prime \prime}$. Her experience of having an abnormal finding that required several follow-up mammograms (rather than preparation from her physicians) led her to feel more prepared for each subsequent test. Juxtaposing Dora's understanding with the other participants' understanding highlights the need for adequate preparation for mammography.

\section{Motivations for at Least One Mammogram}

Participants in this study identified several reasons to have a mammogram. Women described fitting in with others in their age-group, believing the mammogram prevented cancer, wanting early detection of cancer, and having a specific personal or family history of breast cancer.

Stella (58 years): Oh, yeah. Everyone goes through that [mammography] now.

Daisy: If it has to get done, it has to get done.

Polly: So they don't have to cut your boobs off.

Amy (52 years): So you don't get breast cancer.

Participants were generally motivated to have at least 1 mammogram, and the theme of fitting in with their peers was echoed by several women in addition to Stella. Participants also expressed confusion about whether mammography itself prevented breast cancer or was a mode of early detection. Several women doubted that they would not return for subsequent mammograms (2 said no outright, and 6 said, "only if I have to").

\section{Feeling Singled Out During the Test}

Participants were overwhelmed by the logistical aspects of getting a mammogram; many women said they would not return because of such issues as feeling that they did not know what to do and receiving little guidance from staff.

Alice: ... but the people that prep you for it are kind of insensitive, like they just tell you to go in and get changed, one robe on this way, one robe on that way, and they forget that you don't know which robe to put on which way.

Other participants also described feeling singled out or ridiculed during the experience:

Alice: I have a friend who absolutely hated it and stopped going.... She was very big. She was, I think, a double or triple D. It really hurt her, and then the technicians really 
embarrassed her and said, "Boy, you have large boobs." Then she stopped going.

Jessica (66 years): Well I know you have to get up and put your thing in there, but you know I'm not that tall. I'm a short person.

Participants focused on their embarrassment during the experience and the feeling of being singled out. They tended to characterize their experience as due to something other than their intellectual disability ("I'm a one-handed person." "I'm a short person."), although it is possible that their disability itself was an important reason for needing more time. The self-consciousness they experienced clearly made them uncomfortable, and several women said they would not return because of it. In contrast to this experience, only 4 women mentioned pain as an unpleasant aspect of mammography, and 3 women specifically said it did not hurt, leading us to focus more on embarrassment and feeling singled out as the part of the experience that was most difficult.

\section{DISCUSSION}

These data begin to illuminate how women with intellectual disabilities might think differently about mammography when compared with women who are not intellectually disabled. For example, many of the reasons to have a mammogram were similar to those noted for the general population ${ }^{21}$ (physician recommendation, family history, the reassurance of a negative test). Participants also spoke of the understanding that "everyone does it." Researchers have noted that persons with intellectual disabilities have a strong desire to blend in or to pass as nondisabled ${ }^{22}$; this desire may result in the women initially agreeing to a mammogram, because it is recommended for women their age.

We found, however, that several participants' knowledge about breast cancer was incomplete, and some did not even know that the mammogram was a cancer screening test. Women who are not intellectually disabled may not be well-informed about mammography, but most have a general idea what it is. ${ }^{23}$ Women's magazines, bus stop advertisements, and community centers provide information about mammography, but accessing this information requires adequate literacy, which many intellectually disabled women lack. The desire of intellectually disabled women to blend in with the crowd may result in their reluctance to confess they lack knowledge about mammography and ask for information.

Women with intellectual disabilities felt inadequately prepared for and upset by being unfamiliar with mammography. Many of the women we interviewed spoke with mastery about their daily lives- jobs, shopping routines, friends-yet expressed their anxiety over not knowing what to expect from mammography. This anxiety may also be caused in part by difficulties with their adaptive skills that affect activities of daily living (a diagnostic criterion for intellectual disability). Researchers emphasize that intellectual disabilities interact with the environment dynamically ${ }^{1}$; women might appear significantly less disabled while navigating the familiar spheres of home, job, day program, and usual grocery store, but they might appear and feel more disabled in an unfamiliar environment. Thus women may become unmasked during the mammogram so that their disability is more obvious.

Although many women in the general population have similar comments about mammography, ${ }^{24}$ our participants seemed more bothered by its unfamiliarity and their lack of preparation. This difference may be rooted in 2 issues unique to women with intellectual disabilities: they need more time and a more detailed explanation to understand and process elements of the experience, and they want to be perceived as competent, not disabled, which compounds the anxiety of unfamiliar situations. Increasing patients' familiarity with the test may facilitate their ability to complete mammography successfully and to return for subsequent screenings.

One strength of our study is that we collected information by encouraging women with intellectual disabilities to speak for themselves rather than interviewing caregivers or family members. Limitations of the study include its generalizability; although we did reach saturation in terms of the overall themes, we did not do so for the sample of African-American women. Future research is planned to expand the sample of intellectually disabled African-American women and ensure that saturation within that subgroup is reached.

Based on these early findings, we have several preliminary recommendations for preparing intellectually disabled women for mammography. These women and their caregivers, when applicable, should gather as much information about the logistics of the test as possible from friends and family to minimize any unfamiliarity with and anxiety about the details of the day. These women might also benefit by requesting the last appointment of the day and the telling mammography staff that they have a disability and might need more time or additional explanations. Physicians should focus their description of the mammogram to include details about where it occurs, how long it takes, and what the experience will be like, as well as a brief explanation of why it is necessary. They should also consider providing additional resources, such as a video that does not rely on literacy, to prepare intellectually disabled women for mammography. 
To read or post commentaries in response to this article, see it online at http://www.annfammed.org/cgi/content/full/9/2/142.

Key words: Mammography; disability; cancer screening

Submitted June 11, 2010; submitted, revised, October 31, 2010; accepted November 5, 2010.

Previously presented in part at the Northeast Regional meeting of the Family Medicine Education Consortium (October 2010; Hershey, Pennsylvania) and the North American Primary Care Group Annual Meeting (November 2010; Seattle, Washington).

Funding support: This project was supported by Award Number K07CA134547 from the National Cancer Institute ( $\mathrm{NCI})$. The content is solely the responsibility of the authors and does not necessarily represent the official views of the $\mathrm{NCl}$ or the National Institutes of Health.

\section{References}

1. Wisdom JP, McGee MG, Horner-Johnson W, Michael YL, Adams E, Berlin M. Health disparities between women with and without disabilities: a review of the research. Soc Work Public Health. 2010;25(3):368-386.

2. Krahn GL, Hammond L, Turner A. A cascade of disparities: health and health care access for people with intellectual disabilities. Ment Retard Dev Disabil Res Rev. 2006;12(1):70-82.

3. Luckasson R, Coulter DL, Polloway EA, et al. Mental Retardation: Definition, Classification and Systems of Support. Washington, DC: American Association of Mental Retardation; 2002.

4. President's Committee for People with Intellectual Disabilities. Online fact sheet. http://www.acf.hhs.gov/programs/pcpid/pcpid_ fact.html. Accessed Aug 26, 2010.

5. Larson SA, Scott N, Salmi P, Lakin KC. Changes in number and characteristics of people living in state institutions, 1977-2008. Intellect Dev Disabil. 2009;47(4):329-333.

6. Janicki MP, Dalton AJ, Henderson CM, Davidson PW. Mortality and morbidity among older adults with intellectual disability: health services considerations. Disabil Rehabil. 1999;21(5-6):284-294.

7. Iacono T, Sutherland G. Health screening and developmental disabilities. J Policy Pract Intellect Disabil. 2006;3(3):155-163.

8. Sullivan WF, Heng J, Cameron D, et al. Consensus guidelines for primary health care of adults with developmental disabilities. Can Fam Physician. 2006;52(11):1410-1418.
9. Wilkinson JE, Culpepper L, Cerreto M. Screening tests for adults with intellectual disabilities. J Am Board Fam Med. 2007;20(4):399-407.

10. Sullivan SG, Hussain R, Threlfall T, Bittles AH. The incidence of cancer in people with intellectual disabilities. Cancer Causes Control. 2004;15(10):1021-1025.

11. Patja K, Eero P, livanainen M. Cancer incidence among people with intellectual disability. J Intellect Disabil Res. 2001;45(Pt 4):300-307.

12. Davies N, Duff M. Breast cancer screening for older women with intellectual disability living in community group homes. J Intellect Disabil Res. 2001;45(Pt 3):253-257.

13. Sullivan SG, Glasson EJ, Hussain R, et al. Breast cancer and the uptake of mammography screening services by women with intellectual disabilities. Prev Med. 2003;37(5):507-512.

14. Brown AA, Gill CJ. New voices in women's health: perceptions of women with intellectual and developmental disabilities. Intellect Dev Disabil. 2009;47(5):337-347.

15. Tejeda S, Thompson B, Coronado GD, Martin DP. Barriers and facilitators related to mammography use among lower educated Mexican women in the USA. Soc Sci Med. 2009;68(5):832-839.

16. Fernandez ME, Palmer RC, Leong-Wu CA. Repeat mammogram screening among low-income and minority women: a qualitative study. Cancer Control. 2005;12(Suppl 2):77-83.

17. Goldman RE, Risica PM. Perceptions of breast and cervical cancer risk and screening among Dominicans and Puerto Ricans in Rhode Island. Ethn Dis. 2004;14(1):32-42.

18. Kirby S, Hegarty J. Breast awareness within an intellectual disability setting. Eur J Oncol Nurs. 2010;14(4):328-336.

19. Tyler CV, Zyzanski SJ, Panaite V, Council L. Nursing perspectives on cancer screening in adults with intellectual and other developmental disabilities. Intellect Dev Disabil. 2010;48(4):271-277.

20. Charmaz K. Constructing Grounded Theory: A Practical Guide Through Qualitative Analysis. Beverly Hills,CA; Sage Publications, 2006.

21. Hanson K, Montgomery P, Bakker D, Conlon M. Factors influencing mammography participation in Canada: an integrative review of the literature. Curr Oncol. 2009;16(5):65-75.

22. Edgerton RB. The Cloak of Competence. Revised and updated ed. Berkeley, CA: University of California Press; 1993.

23. Ahmed NU, Fort JG, Fair AM, Semenya K, Haber G. Breast cancer knowledge and barriers to mammography in a low-income managed care population. J Cancer Educ. 2009;24(4):261-266.

24. Clark MA, Rogers ML, Wen $X$, et al. Repeat mammography screening among unmarried women with and without a disability. Womens Health Issues. 2009;19(6):415-424. 